\title{
Effect of activation cross section uncertainties in transmutation analysis of realistic low-activation steels for IFMIF
}

\author{
O. Cabellos ${ }^{1,2, a}$, N. García-Herranz ${ }^{1,2}$, J. Sanz $^{1,3}$, S. Reyes ${ }^{4}$, P. Fernández ${ }^{2}$, and B. Fernández ${ }^{2}$ \\ 1 Institute of Nuclear Fusion, UPM, Madrid, Spain \\ 2 Dept. of Nuclear Engineering, UPM, Madrid, Spain \\ 3 Dept. of Power Engineering, UNED, Madrid, Spain \\ ${ }^{4}$ Safety, Environment and Health Group, ITER Joint Work Site, Cadarache Center, France
}

\begin{abstract}
We address uncertainty analysis to draw conclusions on the reliability the activation calculation in the International Fusion Materials Irradiation Facility (IFMIF) under the potential impact of activation cross section uncertainties. The Monte Carlo methodology implemented in ACAB code gives the uncertainty estimates due to the synergetic/global effect of the complete set of cross section uncertainties. An element-by-element analysis has been demonstrated as a helpful tool to easily analyse the transmutation performance of irradiated materials.
\end{abstract}

\section{Introduction}

The subject of transmutation calculations in IFMIF facility using the Intermediate Energy Activation File (IEAF) 2001 [1] or the European Activation File (EAF) 2005 [2] has been covered extensively. At this respect, the IFMIF community has made a lot of work on integral experimental activation benchmarks used to validate several inventory codes [3]: FISPACT, ALARA, ANITA... The calculated results with our $\mathrm{ACAB}[4]$ code are in a quantitative agreement with the experimental data similar to that obtained with other computational approaches already validated for IFMIF applications.

However, very few works have addressed uncertainty analysis to draw conclusions on the reliability of those acceptable results under the potential impact of activation cross section uncertainties. To address the problem in a comprehensive way we have applied a Monte Carlo method (implemented in our inventory $\mathrm{ACAB}$ code) based on a simultaneous random sampling of all the cross section probability density functions. We will make use of the recent EAF2005 uncertainty library to perform this job.

The element-by-element analysis has been demonstrated as a helpful tool to easily analyse the transmutation performance of irradiated materials. The contribution of each source-element to the generation of any transmutant product is obtained in a straightforward way. We calculate the effect of cross section uncertainties in the IFMIF activation of all different elements. We have found that the induced uncertainty in the activation performance of most of the elements is not relevant, but there are a few, but very important ones, that exhibit uncertainties in the activation response with a relevant practical significance in order to assess the acceptability of some intended structural materials for MFE/IFE irradiated in IFMIF.

${ }^{a}$ Presenting author,e-mail: cabellos@din.upm.es

\section{Computational methodology and validation process}

In a previous work [5], transmutation calculations for IFMIF were conducted with an updated version of ACAB radionuclide generation/depletion code that could handle the numerous reaction channels for neutron energies over $20 \mathrm{MeV}$. The activation cross section library processed for IFMIF was the IEAF2001. This library contains the neutron activation cross section files for 679 nuclides, including stable and isomeric states up to $150 \mathrm{MeV}$. We used the group-wise IEAF2001 library in GENDF format with 256 neutron energy structure. IEAF2001 requires only a list of resultant isotopes and cross sections for the production of each one.

In this work, the nuclear data used for activation calculation are those from EAF2005 (62,637 reactions involving 775 different targets from H-1 to Fm-257). EAF2005 relies on a table of fixed reaction types (250) up to $60 \mathrm{MeV}$ with a 211 neutron energy structure.

We have taken XS uncertainty data from the EAF2005/UN library [2]. The uncertainties provided by EAF2005/UN are the most complete uncertainty library in regards to the number of nuclides considered for inventory uncertainty prediction. The information included in this uncertainty file reefers to the relative error in the XS, denoted hereafter as $\Delta_{\mathrm{EAF}}$ (in fact, the information included in these files is $\Delta_{\mathrm{j}, \mathrm{EAF}}^{2}$, where $\mathrm{j}$ is the energy group). Uncertainties $\Delta_{\mathrm{j}, \mathrm{EAF}}$ are provided in a four-energy group structure (up to $60 \mathrm{MeV}$ ) for nonthreshold reactions and in one/two energy group for threshold reactions. It is assumed that errors in XS included in an energy group are $100 \%$ correlated, and that the errors in the different energy groups are uncorrelated. We have taken into account the uncertainties values, $\Delta_{\mathrm{j}, \mathrm{EAF}}$, as three times the experimental standard deviation of $\mathrm{XS}$, that is $\Delta_{\mathrm{j}, \mathrm{EAF}}=3 * \Delta_{\mathrm{j} \text {,EXP }}$, in order to represent a $99.73 \%$ confidence limit. 


\subsection{Monte Carlo methodology}

To assess the impact of cross section uncertainties on transmutation/evolution of irradiated materials, we present the formulation of the Monte Carlo uncertainty analysis implemented into the inventory code ACAB.

The Monte Carlo procedure is based on simultaneous random sampling of all the cross sections involved in the problem, taken from EAF2005/UN. Authors of the EAF library have noted that when evaluating cross sections, the quantity $\log \left(\sigma_{\text {expt }} / \sigma_{\text {calc }}\right)$ was approximately normally distributed. Consequently, it can be said that for any given cross section $\sigma_{\mathrm{j}}$ we can define the random variable $\log \left(\sigma_{\mathrm{j}} / \sigma_{\mathrm{j} 0}\right)$ that follows a normal distribution with mean zero and variance $\Delta_{\mathrm{j}, \mathrm{EXP}}^{2}$. The value $\sigma_{\mathrm{j} 0}$ is the best-estimate $\mathrm{XS}$ from the standard XS file (i.e.: EAF2005/A), and $\Delta_{\mathrm{j}, \mathrm{EXP}}^{2}=\Delta_{\mathrm{j}, \mathrm{EAF}}^{2} / 9\left(\Delta_{\mathrm{j}, \mathrm{EAF}}^{2}\right.$ is given in the uncertainty file, i.e., EAF2005/UN). The probability distributions of isotopic inventory are obtained with this method. Results are obtained for a 1000 history-sampling.

\subsection{Validation}

Our ACAB code has tested with a set of FZK integral activation experiments [6] having a neutron spectrum very close to the IFMIF. Four materials were irradiated: SS316, $\mathrm{F} 82 \mathrm{H}, \mathrm{V}$ and $\mathrm{V}-4 \mathrm{Ti}-4 \mathrm{Cr}$ alloy. The neutron flux intensity is about $4.10 \times 10^{11} \mathrm{n} / \mathrm{cm}^{2} \mathrm{~s}$, assuming a continuous irradiation of $7,525 \mathrm{~s}$. We have adopted the average neutron flux in a 45group energy structure at the centre position of the irradiated steel sample reported in ref. [6], the average neutron energy is $11.2 \mathrm{MeV}$.

In table 1, we present the comparison of activation prediction for a sample of SS316. The calculation-toexperiment ratios $(\mathrm{C} / \mathrm{E})$ obtained by $\mathrm{ACAB} / \mathrm{G}-\mathrm{IEAF}-2001$ and $\mathrm{ACAB} / \mathrm{EAF}-2005$ averaged over the measured decay times are shown in table 1 . Results in column 4 of table 1 $(\Delta \%)$ refers to the relative standard error obtained by Monte Carlo method. For the most important radionuclides to the total activity and contact dose rate $\left({ }^{56} \mathrm{Mn},{ }^{54} \mathrm{Mn},{ }^{57} \mathrm{Ni},{ }^{58} \mathrm{Co}\right.$ and ${ }^{60} \mathrm{Co}$ ) the predictions have demonstrated a reasonable agreement, $\mathrm{C} / \mathrm{E}$ ratios are between 1.02/1.23. For these isotopes, the relative error is less than $10 \%$, therefore, the effect of XS uncertainties on the activation results is insignificant. For the rest of isotopes, larger deviations of $\mathrm{C} / \mathrm{E}$ from unity were found; $\mathrm{C} / \mathrm{E}$ ratios are between $0.03 / 3.73$ and $0.02 / 4.34$ for IEAF2001 and EAF2005, respectively. Larger discrepancies between IEAF2001 and EAF2005 are found: ${ }^{46} \mathrm{Sc},{ }^{48} \mathrm{~V},{ }^{48} \mathrm{Cr}$, ${ }^{52} \mathrm{Mn},{ }^{52} \mathrm{Fe},{ }^{56} \mathrm{Co},{ }^{56} \mathrm{Ni},{ }^{88} \mathrm{Zr}$ and ${ }^{90} \mathrm{Nb}$.

The isotopes with the maximum values of uncertainty are ${ }^{48} \mathrm{Cr}(82.9 \%),{ }^{87 \mathrm{~m}} \mathrm{Y}(77.3 \%)$ and ${ }^{90} \mathrm{Mo}(71.5 \%)$, their main build-up sequences for isotope generation are: i) ${ }^{48} \mathrm{Cr}$ is mainly due to the reactions ${ }^{50} \mathrm{Cr}(\mathrm{n}, 3 \mathrm{n}){ }^{48} \mathrm{Cr}$, ii) ${ }^{87 \mathrm{~m}} \mathrm{Y}$ the critical reaction is ${ }^{92} \mathrm{Mo}(\mathrm{n}, \mathrm{d} \alpha){ }^{87 \mathrm{~m}} \mathrm{Y}$, and iii) ${ }^{90} \mathrm{Mo}$ the critical one is ${ }^{92} \mathrm{Mo}(\mathrm{n}, 3 \mathrm{n}){ }^{90} \mathrm{Mo}$. The effective 1-group cross section uncertainties (in \%) processed by EAF2005/UN for these reactions are: $67 \%, 70 \%$ and $67 \%$, respectively.
Table 1. Calculation-to-experiment average ratios for the activity inventories induced in the SS316 intermediate energy activation experiment [6].

\begin{tabular}{|c|c|c|c|}
\hline & IEAF2001 & \multicolumn{2}{|c|}{ EAF2005 } \\
\hline Isotope & $\mathrm{C} / \mathrm{E}$ & $\mathrm{C} / \mathrm{E}$ & $\Delta \%$ \\
\hline Sc 46 & 1.66 & 2.46 & 10.8 \\
\hline Sc 48 & 1.28 & 1.74 & 15.3 \\
\hline V 48 & 2.72 & 1.28 & 29.6 \\
\hline $\mathrm{Cr} 48$ & 3.73 & 1.54 & 82.9 \\
\hline $\mathrm{Cr} 49$ & 0.82 & 0.71 & 3.8 \\
\hline Cr 51 & 1.00 & 1.09 & 3.3 \\
\hline Mn 52 & 3.13 & 1.31 & 26.8 \\
\hline Mn 54 & 1.02 & 1.16 & 9.4 \\
\hline Mn 56 & 1.23 & 1.22 & 0.6 \\
\hline Fe 52 & 1.44 & 4.34 & 19.9 \\
\hline Fe 59 & 1.07 & 1.18 & 17.8 \\
\hline Co 55 & 2.12 & 1.45 & 64.1 \\
\hline Co 56 & 2.98 & 1.31 & 27.7 \\
\hline Co 57 & 1.02 & 1.12 & 0.9 \\
\hline Со 58 & 1.20 & 1.19 & 3.0 \\
\hline Co 60 & 1.12 & 1.03 & 3.3 \\
\hline Co 61 & 2.26 & 2.66 & 17.5 \\
\hline Ni 56 & 1.57 & 0.37 & 45.2 \\
\hline Ni 57 & 1.19 & 1.22 & 0.5 \\
\hline Y $87 \mathrm{~m}$ & 0.07 & 0.15 & 77.3 \\
\hline Y 87 & 0.46 & 0.82 & 63.3 \\
\hline Y 88 & 1.00 & 0.61 & 25.4 \\
\hline Zr 86 & 0.03 & 0.03 & 73.7 \\
\hline Zr 88 & 0.99 & 0.45 & 9.2 \\
\hline Zr 89 & 1.20 & 1.48 & 5.4 \\
\hline Zr 97 & 0.03 & 0.02 & 3.0 \\
\hline $\mathrm{Nb} 90$ & 0.58 & 1.80 & 34.2 \\
\hline $\mathrm{Nb} 92 \mathrm{~m}$ & 1.51 & 1.46 & 4.1 \\
\hline $\mathrm{Nb} 95$ & 1.53 & 1.65 & 6.1 \\
\hline $\mathrm{Nb} 95 \mathrm{~m}$ & 1.18 & 0.84 & 9.4 \\
\hline $\mathrm{Nb} 96$ & 1.65 & 1.88 & 8.5 \\
\hline Мo 90 & 1.64 & 1.97 & 71.5 \\
\hline Мo 93m & 2.50 & 1.81 & 44.2 \\
\hline Мо 99 & 1.18 & 1.29 & 1.7 \\
\hline Tc 99m & 1.19 & 1.30 & 1.4 \\
\hline
\end{tabular}

\section{Uncertainty analysis for element-by-element transmutation}

We have considered the IFMIF scenario $\left(7.30 \times 10^{14} \mathrm{n} / \mathrm{cm}^{2} \mathrm{~s}\right.$, $\langle E\rangle \sim 5.64 \mathrm{MeV})$ to perform an uncertainty analysis for element-by-element transmutation under 1 year of irradiation time. Firstly, in table 2 we present the $\mathrm{H}$ and $\mathrm{He}$ gas production and the evolution of solid transmutants for the major and minor steel constituents. Secondly, we predict the relative error or coefficient of variation (ratio between standard deviation and the mean) of the final concentration of each element.

Normally, for gas production, the largest uncertainties are in $\mathrm{He}$ production. In the case of $\mathrm{Fe}$, uncertainties for $\mathrm{H}$ and $\mathrm{He}$ transmutants are $7.6 \%$ and $5.3 \%$, respectively. For Ni, $7.0 \%$ and $6.7 \%$, for $\mathrm{H}$ and $\mathrm{He}$ transmutants, respectively. 
Table 2. Transmutants (appm) and relative error (\%) of typical intended and impurities elements in reduced activation steels under 1 year of irradiation time in HFTM/IFMIF. Calculations performed with ACAB/EAF2005.

\begin{tabular}{|c|c|c|c|c|c|c|c|c|c|c|c|c|c|c|c|}
\hline & & \multicolumn{2}{|c|}{$\mathrm{H}$} & \multicolumn{2}{|c|}{$\mathrm{He}$} & \multicolumn{2}{|c|}{$\mathrm{Z}-2$} & \multicolumn{2}{|c|}{ Z-1 } & \multicolumn{2}{|c|}{ Z } & \multicolumn{2}{|c|}{$\mathrm{Z}+1$} & \multicolumn{2}{|c|}{$\mathrm{Z}+2$} \\
\hline $\mathrm{Z}$ & Element & appm & $\%$ & appm & $\%$ & appm & $\%$ & appm & $\%$ & appm & $\%$ & appm & $\%$ & appm & $\%$ \\
\hline 5 & B & 809 & 8.7 & 3473 & 8.4 & 2461 & 10.8 & 352 & 8.6 & -3360 & 8.1 & 0 & 16.1 & 0 & 38.0 \\
\hline 6 & $\mathrm{C}$ & 425 & 17.8 & 3425 & 56.9 & 477 & 7.0 & 358 & 20.6 & -1847 & 35.3 & 0 & 30.0 & 0 & 78.3 \\
\hline 7 & $\mathrm{~N}$ & 2712 & 15.7 & 2464 & 16.1 & 1831 & 5.4 & 2699 & 15.8 & -4847 & 9.9 & 0 & 59.7 & 0 & 103.6 \\
\hline 8 & $\mathrm{O}$ & 359 & 10.6 & 1393 & 10.1 & 1359 & 10.2 & 216 & 15.9 & -1606 & 9.0 & 0 & 49.5 & 0 & 51.8 \\
\hline 13 & $\mathrm{Al}$ & 1084 & 9.3 & 677 & 10.0 & 230 & 6.4 & 1097 & 10.7 & -1355 & 8.9 & 13 & 12.1 & 0 & 41.0 \\
\hline 14 & $\mathrm{Si}$ & 2304 & 4.2 & 1199 & 5.3 & 1248 & 5.9 & 926 & 5.8 & -2195 & 4.1 & 1 & 14.9 & 0 & 33.1 \\
\hline 15 & $\mathrm{P}$ & 3929 & 20.5 & 883 & 21.8 & 257 & 73.9 & 3608 & 22.4 & -3907 & 21.3 & 23 & 30.3 & 0 & 95.3 \\
\hline 16 & $S$ & 4294 & 11.2 & 2677 & 14.5 & 2852 & 14.2 & 1512 & 27.2 & -4397 & 13.0 & 1 & 13.7 & 0 & 27.2 \\
\hline 22 & $\mathrm{Ti}$ & 988 & 9.7 & 406 & 34.9 & 382 & 37.3 & 317 & 11.7 & -701 & 21.0 & 1 & 14.6 & 0 & 18.9 \\
\hline 23 & V & 658 & 9.8 & 81 & 6.9 & 5 & 35.2 & 666 & 12.6 & -724 & 12.3 & 54 & 11.3 & 0 & 38.7 \\
\hline 24 & $\mathrm{Cr}$ & 1106 & 6.5 & 265 & 8.4 & 304 & 7.9 & 1906 & 3.8 & -2212 & 3.5 & 0 & 19.0 & 0 & 21.5 \\
\hline 25 & $\mathrm{Mn}$ & 845 & 22.2 & 200 & 40.4 & 124 & 64.7 & 1563 & 12.1 & -1775 & 11.6 & 87 & 10.1 & 0 & 34.0 \\
\hline 26 & $\mathrm{Fe}$ & 1440 & 7.6 & 288 & 5.3 & 392 & 8.9 & 1074 & 7.5 & -1502 & 7.3 & 0 & 12.5 & 0 & 19.1 \\
\hline 27 & Co & 1235 & 20.2 & 260 & 38.6 & 150 & 66.3 & 2960 & 9.2 & -3132 & 9.3 & 14 & 14.7 & 0 & 44.3 \\
\hline 28 & $\mathrm{Ni}$ & 5808 & 7.0 & 1148 & 6.7 & 4112 & 5.8 & 2364 & 3.2 & -6629 & 4.5 & 1 & 10.2 & 0 & 12.7 \\
\hline 29 & $\mathrm{Cu}$ & 2009 & 19.0 & 317 & 5.1 & 259 & 4.9 & 4146 & 9.2 & -4906 & 7.8 & 483 & 3.2 & 0 & 32.8 \\
\hline 39 & Y & 789 & 22.5 & 53 & 10.0 & 8 & 11.5 & 3101 & 6.5 & -3226 & 6.3 & 111 & 15.3 & 0 & 39.2 \\
\hline 41 & $\mathrm{Nb}$ & 735 & 15.3 & 119 & 14.4 & 59 & 12.3 & 2268 & 5.6 & -2349 & 5.4 & 2 & 15.5 & 0 & 55.0 \\
\hline 42 & Mo & 1119 & 16.2 & 104 & 10.0 & 231 & 14.9 & 1035 & 17.0 & -1934 & 9.6 & 607 & 7.4 & 30 & 15.8 \\
\hline 73 & $\mathrm{Ta}$ & 191 & 22.5 & 19 & 26.7 & 9 & 46.9 & 4698 & 10.4 & -7052 & 8.1 & 2345 & 10.6 & 0 & 135.7 \\
\hline 74 & W & 204 & 12.0 & 26 & 11.8 & 102 & 25.9 & 1677 & 12.7 & -3443 & 6.8 & 1660 & 4.5 & 3 & 11.2 \\
\hline
\end{tabular}

Regarding major steel constituents, the transmutation of $\mathrm{C}$, $\mathrm{P}$ and Ti elements have the largest uncertainties, 35.3\%, 21.3\% and $21 \%$ respectively. For Fe, uncertainty is $7.3 \%$.

\section{Uncertainty analysis for steels: EUROFER}

Firstly, to assess the effect of the uncertainties we have calculated the contact $\gamma$-dose rate for EUROFER under 1 fpy of irradiation time in HFTM/IFMIF [7]. The uncertainty analysis has been performed using ACAB code with EAF2005/UN library.

Figure 1 shows that from the moment of shutdown up to $\sim 10 \mathrm{~h}$, the relative error is less than $10 \%$. Nevertheless, the uncertainty analysis results show that for times over $\sim 24 \mathrm{~h}$ the relative error in the contact dose rate can be as large as $23 \%$ (see fig. 1). Therefore, the effect of XS uncertainties on the activation results during times relevant for maintenance activities and from waste management point of view could be important.

However, in this work we have focused on the uncertainty analysis for transmutation. The element-by-element transmutation presented in table 2 leads to predict the transmutation performance of any material irradiated in IFMIF.

Table 3 shows the main transmutants for EUROFER under 1 fpy in HFTM/IFMIF using IEAF2001 and EAF2005. H and He transmutants are larger with IEAF2001 (iron produces the most important levels of $\mathrm{H}$ and $\mathrm{He}, \sim 90 \%$ and $\sim 80 \%$ respectively). After one year of irradiation, these gaseous transmutant concentrations can be comparable to some initial steel constituents.

In column 5 table 3, we predict the relative error of each element. The transmutant uncertainty analysis for $\mathrm{H}$ and $\mathrm{He}$
IFMIF.

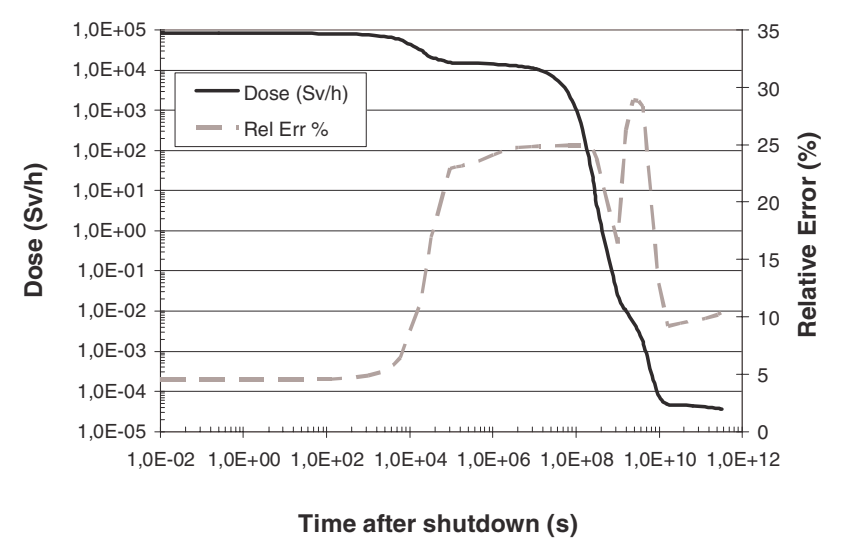

Fig. 1. Contact dose rate $(\mathrm{Sv} / \mathrm{h})$ and the relative error $(\%)$ for EUROFER under 1 year of irradiation time in HFTM/IFMIF.

shows a relative error of $7.3 \%$ for $\mathrm{H}$, and $5.6 \%$ for He. For $\mathrm{C}(74.3 \%), \mathrm{P}(41 \%)$ and $\mathrm{Nb}(34.8 \%)$ we have predicted the largest transmutant uncertainties.

\section{Conclusions}

The ACAB code is able to deal with transmutation calculations in IFMIF facility using IEAF2001 and EAF2005. A more complete benchmark of ACAB against the already validated computational methodologies used for activation and transmutation calculations has been performed.

In addition, the impact of potential activation cross section uncertainties on the transmutation calculations is assessed. 
Table 3. Transmutation (appm) of EUROFER constituents under 1 year of irradiation time in the HFTM/IFMIF. Calculations performed with ACAB/IEAF-2001 and EAF2005.

\begin{tabular}{ccccc}
\hline & INITIAL & IEAF2001 & EAF2005 & Rel Err \\
\hline Element & appm & appm & appm & $\%$ \\
\hline $\mathrm{H}$ & 0 & 1450 & 1397 & 7.3 \\
$\mathrm{He}$ & 0 & 307 & 304 & 5.6 \\
$\mathrm{Li}$ & 0 & 0.3 & 0.1 & 2.6 \\
$\mathrm{Be}$ & 0 & 2 & 2 & 6.9 \\
$\mathrm{~B}$ & 51 & 4 & 4 & 10.4 \\
$\mathrm{C}$ & 4860 & -6 & -5 & 74.3 \\
$\mathrm{~N}$ & 1191 & -4 & -6 & 10.4 \\
$\mathrm{O}$ & 347 & -1 & -1 & 9,2 \\
$\mathrm{Mg}$ & 0 & 2 & 1 & 5,4 \\
$\mathrm{Al}$ & 206 & 1 & 1 & 9,3 \\
$\mathrm{Si}$ & 990 & -2 & -2 & 7,6 \\
$\mathrm{P}$ & 90 & 0.04 & -0.2 & 41,0 \\
$\mathrm{~S}$ & 87 & -0.4 & -0.4 & 14,0 \\
$\mathrm{Ti}$ & 116 & 29 & 31 & 7,9 \\
$\mathrm{~V}$ & 2183 & 211 & 182 & 3,4 \\
$\mathrm{Cr}$ & 96233 & 164 & 141 & 25.0 \\
$\mathrm{Mn}$ & 4048 & 970 & 944 & 7.8 \\
$\mathrm{Fe}$ & 885882 & -1377 & -1330 & 7.6 \\
$\mathrm{Co}$ & 47 & 0.1 & -0.02 & 15.0 \\
$\mathrm{Ni}$ & 47 & -0.1 & -0.1 & 16.6 \\
$\mathrm{Cu}$ & 44 & -0.2 & -0.2 & 8.0 \\
$\mathrm{Nb}$ & 6 & 0.01 & 0.02 & 34.8 \\
$\mathrm{Mo}$ & 29 & -0.1 & -0.1 & 10.1 \\
$\mathrm{Hf}$ & 0 & 1 & 1 & 11.0 \\
$\mathrm{Ta}$ & 215 & 4 & 4 & 19.1 \\
$\mathrm{~W}$ & 3327 & -10 & -11 & 7.4 \\
$\mathrm{Re}$ & 0 & 5 & 6 & 4.5 \\
$\mathrm{Os}$ & 0 & 0.01 & 0.01 & 0.0 \\
\hline & & & &
\end{tabular}

The implemented Monte Carlo method in ACAB is applied to transmutation uncertainty analysis, showing its capability to deal with comprehensive cross section uncertainty data.

We have assessed the effect of the uncertainties in the contact $\gamma$-dose rate for EUROFER under 1 fpy of irradiation time in HFTM/IFMIF. The uncertainty analysis results showed that for times over $\sim 24 \mathrm{~h}$ the relative error in the contact dose rate can be as large as $23 \%$.

We have calculated the effect of cross section uncertainties in the IFMIF activation of all different elements. For EUROFER, uncertainties in $\mathrm{H}$ and $\mathrm{He}$ transmutants are $7.3 \%$ and $5.6 \%$, respectively. We have found significant uncertainties in the transmutation response for $\mathrm{C}, \mathrm{P}$ and $\mathrm{Nb}$.

Work performed under the Polytechnical University of Madrid Project M0500204123, Ministerio de Educación y Ciencia Program ECI/1920/2006 and European Union keep-in-touch Program on IFE.

\section{References}

1. U. Fischer, D. Leichtle, U.V. Möllendorff et al., Intermediate Energy Activation File IEAF-2001, NEA data bank programme library, package NEA-1656/01, 2001.

2. R.A. Forrest, J. Kopecky, J.-Ch. Sublet, The European Activation File: EAF-2005 cross section library, EURATOM/UKAEA Fusion, UKAEA FUS 515, 2005.

3. U. Fischer, S. Simakov, U.V. Möllendorff, P. Pereslavtsev, P. Wilson, Validation of Activation Calculations Using the Intermediate Energy Activation File IEAF-2001, Fus. Eng. Des. 69, $485(2003)$

4. J. Sanz, ACAB Activation Code for Fusion Applications: User's Manual V5.0, Lawrence Livermore National Laboratory UCRLMA-143238, February 2000.

5. O. Cabellos, J. Sanz, N. García-Herranz, S. Díaz, S. Reyes, S. Piedloup, Transmutation analysis of realistic low-activation steels for magnetic fusion reactors and IFMIF, J. Nucl. Mater. (to be published).

6. U.V. Moellendorf, F. Maekawa et al., A nuclear simulation experiment for the International Fusion Materials Irradiation Facility (IFMIF), Forschungszentrum Karlsruhe, Bericht FZKA 6764, October 2002.

7. U. Fischer, S.P. Simakov, P.P.H. Wilson, Transmutation Behaviour of EUROFER Under Irradiation in IFMIF Test Facility and Fusion Power Reactors, J. Nucl. Mater. 329-333, 228 (2004). 